\title{
SISTEM NAVIGASI MOBILE ROBOT DALAM RUANGAN BERBASIS AUTONOMOUS NAVIGATION
}

\author{
Dwiky Erlangga ${ }^{1, a}$, Endang $D^{2, b}$, Rosalia $\mathrm{H} \mathrm{S}^{3, \mathrm{c}}$, Sunarto ${ }^{4, \mathrm{~d}}$, \\ Kuat Rahardjo T.S ${ }^{5, \mathrm{e}}$, Ferrianto $\mathrm{G}^{6, \mathrm{f}}$ \\ ${ }^{1}$ Jurusan Teknik Elektro Fakultas Teknologi Industri Universitas Trisakti \\ 2 Jurusan Teknik Elektro Fakultas Teknologi Industri Universitas Trisakti \\ adwikyerlangga@std.ac.id, bedjuana@trisakti.ac.id, crosalia@trisakti.ac.id, dyuhaw@hotmail.com, \\ ekuatrts@trisakti.ac.id, ferrianto@trisakti.ac.id
}

\begin{abstract}
Abstrak.
Autonomous-navigation kebutuhan mutlak dalam mobile-robotic, yang terdiri dari empat komponen utama yaitu: perception, localization, path-planning, dan motion-control. Mobile robot membuat peta ruang agar dapat melaksanakan perintah untuk berpindah dari suatu tempat ke tempat lain dengan metode autonomous-navigation. Pembuatan peta menggunakan algoritma Simultaneous-Localization-and-Mapping(SLAM) yang mengolah data dari sensor RGB-D camera dan bumper yang di konversi ke laser-scan dan point-cloud digunakan untuk memperoleh perception. Sedangkan wheel-encoder dan gyroscope digunakan untuk mendapatkan data odometry yang digunakan untuk untuk membangun peta perjalanan dengan algoritma SLAM, gmapping dan melakukan autonomous-navigation. Sistem terdiri dari tiga sub-sistem yaitu: sensor sebagai input, single-board-computer untuk proses, dan actuator sebagai penggerak. Autonomous-navigation diatur melalui navigation-stack dengan menggunakan algoritma Adaptive-Monte-CarloLocalization(AMCL) untuk localization dan global-planning, sedangkan algoritma DynamicWindow-Approach(DWA) dengan Robot-Operating-System-(ROS) untuk local-planning. Hasil dari pengujian menunjukkan sistem dapat memberikan data depth yang dikonversi ke-laser-scan, data bumper, dan data odometry kepada single-board-computer berbasis ROS sehingga mobile-robot yang dikendalikan secara teleoperasi dari workstation dapat membangun peta grid 2 dimensi dengan akurasi total error rate sebesar $0.987 \%$. Dengan menggunakan peta, data dari sensor, dan odometry tersebut mobile-robot dapat melakukan autonomous-navigation secara konsisten dan mampu melakukan path-replanning, menghindari rintangan-rintangan statis dan terus menerus melakukan localization untuk mencapai titik tujuan.
\end{abstract}

Kata kunci. Mobile-robot, Autonomous-navigation, path-replanning.

\section{Abstract.}

Autonomous navigation is absolutely necessary in mobile-robotic, which consists of four main components, namely: perception, localization, path-planning, and motion-control. Mobile robots create maps of space so that they can carry out commands to move from one place to another using the autonomous-navigation method. Map making using the SimultaneousLocalization-and-Mapping (SLAM) algorithm that processes data from the RGB-D camera sensor and bumper converted to laser-scan and point-cloud is used to obtain perception. While the wheel- 
encoder and gyroscope are used to obtain odometry data which is used to construct travel maps with the SLAM algorithm, gmapping and performing autonomous navigation. The system consists of three sub-systems, namely: sensors as inputs, single-board computers for processes, and actuators as movers. Autonomous-navigation is regulated through the navigation-stack using the Adaptive-Monte-Carlo-Localization (AMCL) algorithm for localization and global-planning, while the Dynamic-Window-Approach (DWA) algorithm with Robot-Operating-System-(ROS) for localplanning. The results of the test show the system can provide depth-data that is converted to laserscan, bumper data, and odometry data to single-board-computer-based ROS so that mobilecontrolled teleoperating robots from workstations can build 2-dimensional grid maps with total accuracy error rate of $0.987 \%$. By using maps, data from sensors, and odometry the mobile-robot can perform autonomous-navigation consistently and be able to do path-replanning, avoid static obstacles and continue to do localization to reach the destination point.

Keywords. Mobile-robot, Autonomous-navigation, path-replanning.

\section{PENDAHULUAN}

Perkembangan teknologi digital telah meningkatkan kemampuam dari mikroprosesor sehingga dapat membentuk single board computer, yang memungkinkan membentuk algorithma rumit yang dibutuhkan membentuk robot. Mobil robot yang dimulai dengan pergerakan manual, dikembangkan menjadi line follower dan saat sekarang telah memungkinkan untuk melakukan penelitian dalam membentuk Mobile-Robot yang bergerak secara autonomous.

Kebutuhan akan Autonomous-Mobile-robot dalam ruangan dapat dipergunakan antara lain sebagai pengantar barang(R. Siegwart,2011), seperti misalnya pada restoran; super market; resepsionis di hotel; pemandu wisata didalam ruang museum, dan home care robot (M.Boisy,2007) untuk memberikan bantuan pada orang lanjut usia maupun penyandang disabilitas, dan lain-lain.

\section{Studi Pustaka:}

Untuk dapat melakukan fungsi-fungsi agar dapat beroperasi di dalam ruangan secara autonomous, memerlukan empat komponen utama yaitu:

1) Perception: robot harus dapat membentuk peta ruangan tempat beroperasi dan menganalisa rintangan dan jalan yang dapat dilalui menuju lokasi yang ditentukan dalam ruang. Dalam membentuk peta menggunakan RGB-D camera yang merupakan camera 3D yang digunakan untuk mengenali lingkungan dengan membaca secara depth level dari objek-objek pada lingkungan. Hasil pembacaan tersebut diproses oleh single board computer dikonversi menjadi pembacaan laser scan untuk membentuk peta ruangan (gmapping). Dengan Algoritma simultaneous localization and mapping (SLAM) gmapping diolah menggunakan versi dari Rao-Blackwellized Particle Filter untuk mengkonversi gambar menjadi grid map yang menghasilkan pengurangan ukuran sampling, sehingga secara efektif mengurangi waktu komputasi (G. Grisetti, 2005)(G. Grisetti, 2007).

2) Localization: Setelah robot bergerak, harus mampu untuk mengidentifikasi posisinya terhadap tujuan (odometry) dan mengevaluasi untuk menghindari rintangan yang ada (T.Pire, 2015). Untuk mengetahui lokasi yang telah ditempuh, selain menggunakan RGB-D camera untuk mengenali lingkungan dengan membaca depth level dari objek-objek pada lingkungan membutuhkan sensor 
wheel encoder dan gyroscope untuk mendapatkan data odometry yang berupa posisi, orientasi, dan kecepatan robot, dari motor penggerak robot yang digerakkan oleh driver motor di single board computer. Untuk mencegah terjadinya benturan akibat perubahan mendadak dari peta ruangan, perlu ditambah dengan sensor Bumper yang berfungsi untuk melindungi robot dari benturan terhadap objek yang muncul mendadak maupun objek yang tidak dapat dideteksi RGB-D camera karena transparent maupun terlalu rendah (dianggap datar).

3) Path planning: Agar robot dapat menuju lokasi yang diperintahkan, harus dapat menentukan jalur jalan yang layak dan optimal dari lokasinya saat ini (path planning) untuk menuju ke tujuan yang ditentukan sekaligus menghindari rintangan. Path planning ini diperoleh menggunakan gmaping dan Robot Operating System (ROS) yang memanfaatkan object-oriented programming (OOP), dengan mengolah objek-objek atau data untuk dibandingkan dengan data yang diperoleh dari sistem modular Sensor untuk mengestimasi depth per piksel berdasarkan referensi pattern yang paling sesuai dengan pattern yang telah diperoleh dari proyeksi (R. Zapata, 2012). ROS adalah opensource middleware framework berbasis Unix memiliki arsitektur modular, fleksibel dan robust. pada aplikasi robotika (Q. Morgan, 2012). Struktur dari ROS mencakup tiga level konsep yang berbeda yaitu filesystem level, computational graph level, dan community level (F. Enrique, 2015) yang dipakai untuk membentuk global planning sebagai path planning. Sedangkan setelah robot berjalan, untuk membentuk Local Path Planing dilakukan dengan menggunakan algorithma Monte carlo localization (MCL) adalah algoritma localization yang merepresentasikan belief bel $(x)$ dengan partikel di dalam Adaptive monte carlo localization (AMCL) yang di implementasikan dengan metode Kullback-Leibler divergence KLD-sampling (S. Thrun, 2005) (D. Fox, 2003), serta untuk dapat menghindari rintangan di dalam local planning menggunakan algoritma Dynamic Window Approach (DWA).

4) Motion control: robot harus dapat melakukan manuver ke tujuan berdasarkan peta yang telah dibuat. Robotika adalah bidang ilmu yang merasakan, mengamati, dan memanipulasi dunia fisik melalui peralatan-peralatan penggerak (actuator) yang dikendalikan computer (S. Thrun, 2015).

\section{METODOLOGI PENELITIAN}

Dalam implementasi "Sistem Navigasi Mobile Robot dalam ruangan berbasis Autonomous Navigation" membutuhkan tiga sub sistem perangkat keras yaitu: sub sistem sensor yang terdiri dari RGB-D camera, Bumper, Gyroscope dan Wheel encoder yang akan memberikan masukan kepada sub sistem navigation command yang mengunakan single board computer untuk mengolah seluruh data yang masuk melalui sensor. Hasil pengolahan data navigasi yang merupakan perintah untuk dikirim ke sub system actuator yang akan menjalankan robot menuju lokasi yang diperintahkan seperti dapat dilihat pada gambar 1.

Dari ketiga sub system tersebut, yang paling berperan penting adalah sub system navigation command yang mengolah berbagai masukan dari sub system sensor menjadi perintah untuk menggerakkan sub system actuator yang menjalankan robot.

Sub system navigation command harus menggunakan sistem operasi ROS untuk memproses data di dalam jaringan peer-to-peer agar terjadi interaksi antara sistem dengan sensor dan actuator dan sesuai algorithma yang diberikan melalui SLAM untuk membuat peta ruang dan MCL untuk menentukan path dari titik awal ke tujuan yang diperintahkan dan AMCL untuk melakukan perubahan path jika menghadapi rintangan dalam perjalanan. ROS memiliki: 
a. Nodes: adalah sebuah atau suatu kelompok I/O yang ditugaskan untuk melayani sebuah process yang merupakan bagian dari robot dimana data diterima untuk diproses dan hasil komputasi dikirimkan ke sub system actuator untuk melakukan tugasnya.

b. Master: program utama yang berfungsi untuk mempersiapkan koneksi antara node.

c. Parameter Server: menyediakan nilai acuan suatu node ketika node sedang aktif dan melakukan komputasi dengan node lainnya.

d. Message (Pesan): ROS memiliki banyak tipe message, dan user membuat tipe message sendiri agar Node dapat berkomunikasi satu dengan lainnya.

e. Topics (Topik): Setiap message memiliki nama topic (publish topic) yang disiapkan, agar dapat diarahkan oleh ROS untuk pelaksanaan suatu fungsi.

f. Services: pelayanan publish topic dari suatu node ke seluruh node, maupun dari sebuah node ke node tertentu menggunakan unique name.

g. Bags: wadah untuk menyimpan dan memutar ulang data ROS message. Bag digunakan untuk menyimpan data-data sensor, yang diperlukan untuk mengembangkan dan menguji algoritma.

Koordinasi antar berbagai sub system tersebut, dimungkinkan melalui masing-masing program yang dibuat dalam membentuk fungsi robot didalam ROS.

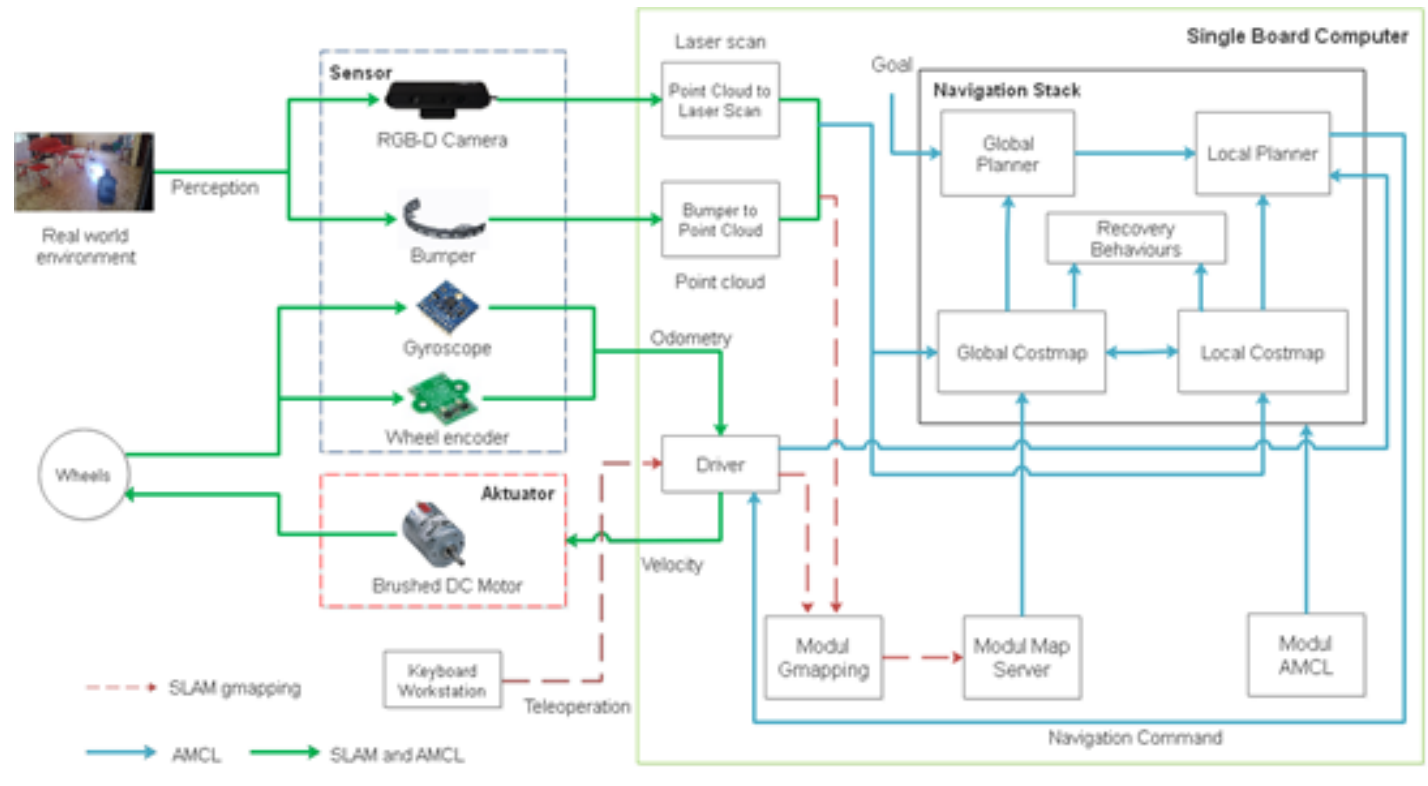

Gambar.1 Diagram sistem navigasi mobile robot dalam ruangan berbasis Autonomous Navigation

Simultaneous-Localization-and-Mapping (SLAM) Gmapping

Data yang berasal dari RGB-D camera dipergunakan untuk membuat pemetaan ruangan secara global, program SLAM dipergunakan untuk membentuk gmapping ruangan, dengan teknik mapping occupancy grid map yang memiliki alur seperti pada flowchart pada gambar 2. Flowchart menjelaskan proses SLAM dengan algoritma gmapping membentuk peta ruangan.

Monte Carlo Localization (MCL)

Gmapping oleh program yang dimasukkan pada algorithma MCL dihitung untuk membentuk global path seperti dapat dilihat pada Gambar 4. Flowchart proses global planning. 
AMCL melakukan perhitungan untuk membentuk local path yang akan dilintasi agar mobile robot dapat melakukan autonomous navigation seperti dapat dilihat pada gambar 3. Flowchart proses AMCL.

AMCL setiap saat melakukan localization untuk menentukan belief pada waktu t $b e(x)$ dengan menggunakan particle filter dimana belief robot terhadap posisinya pada real world environment diestimasi oleh probability distribution dengan data-data yang diperoleh dari gyroscope dan wheel encoder, sehingga apabila menemui rintangan dapat melakukan perhitungan ulang untuk mendapatkan local path yang baru untuk mencapai tujuan seperti pada Gambar 5. Flowchart proses local planning.
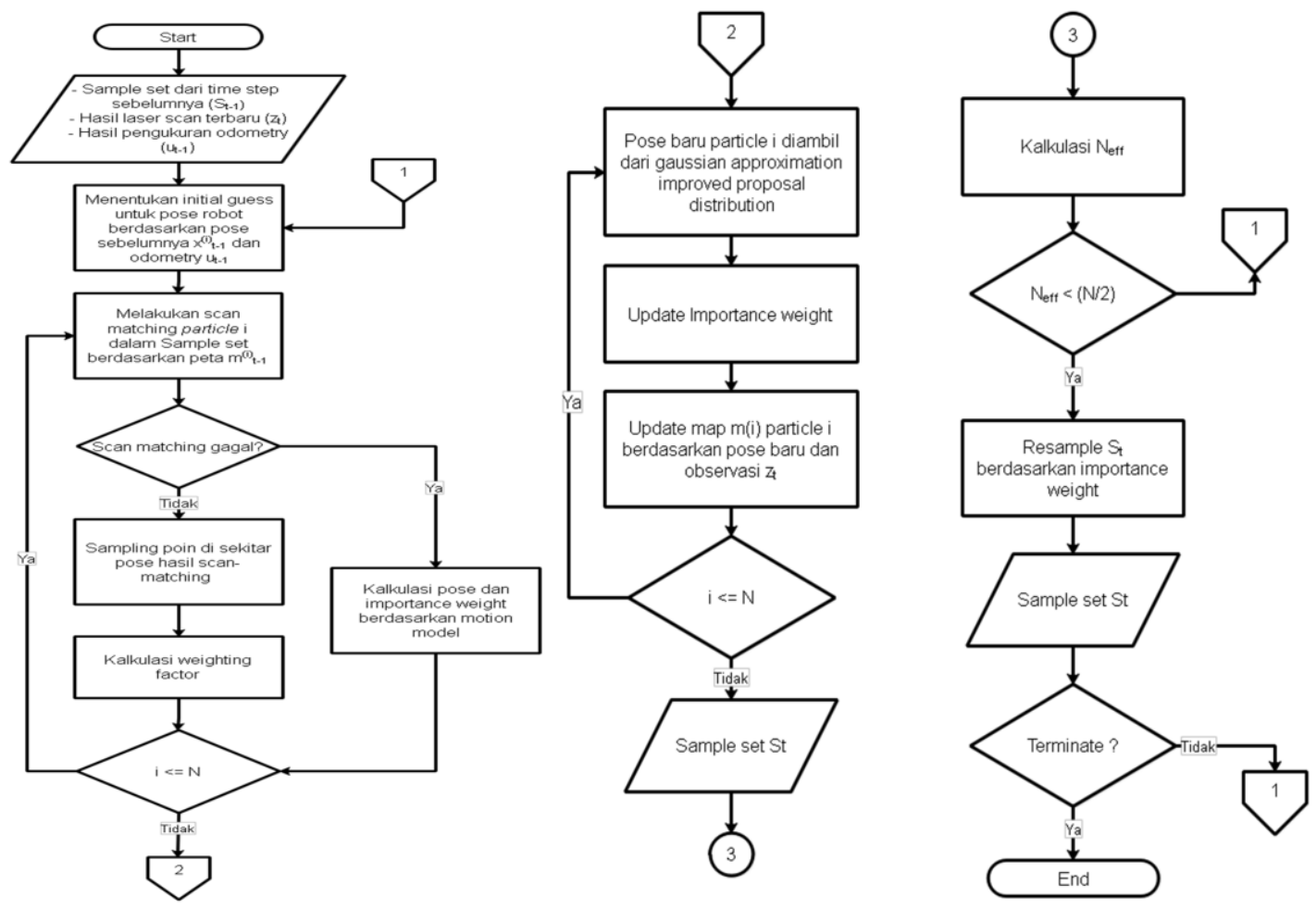

Gambar 2. Flowchart proses SLAM gmapping 

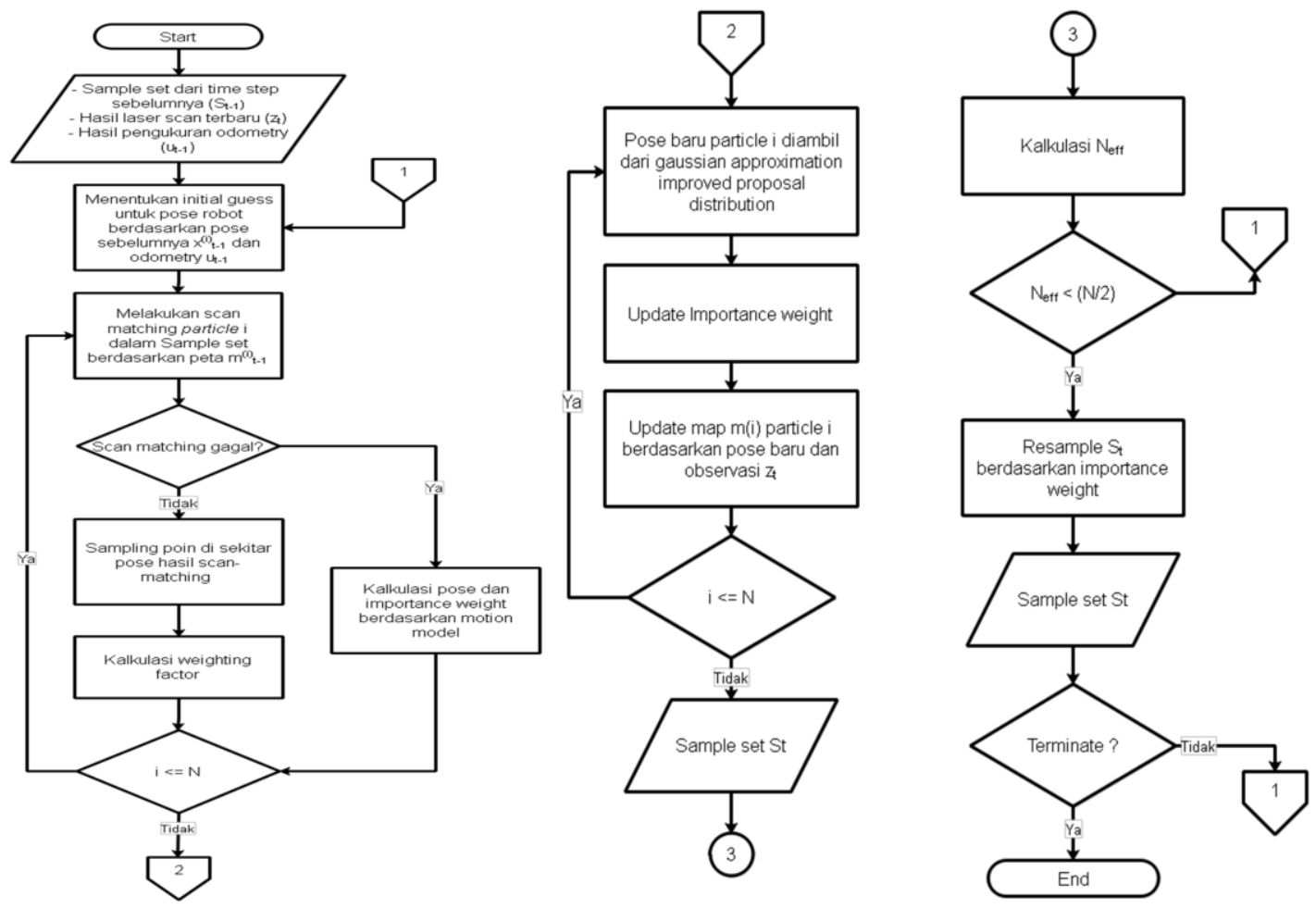

Gambar 2. Flowchart proses SLAM gmapping

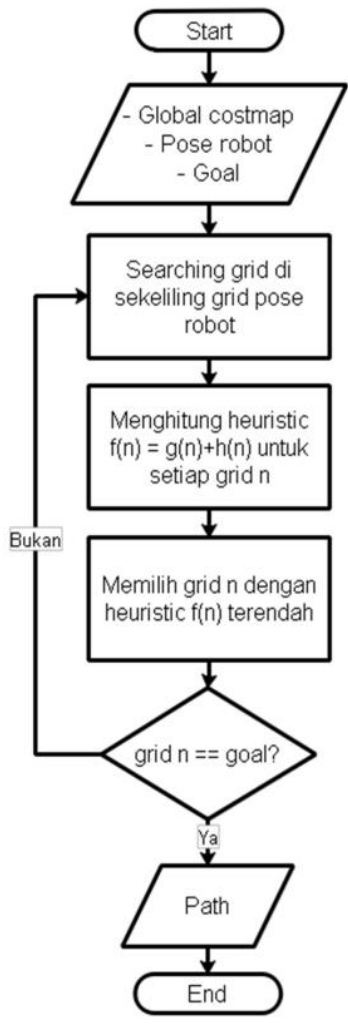

Gambar 4. Flowchart proses global

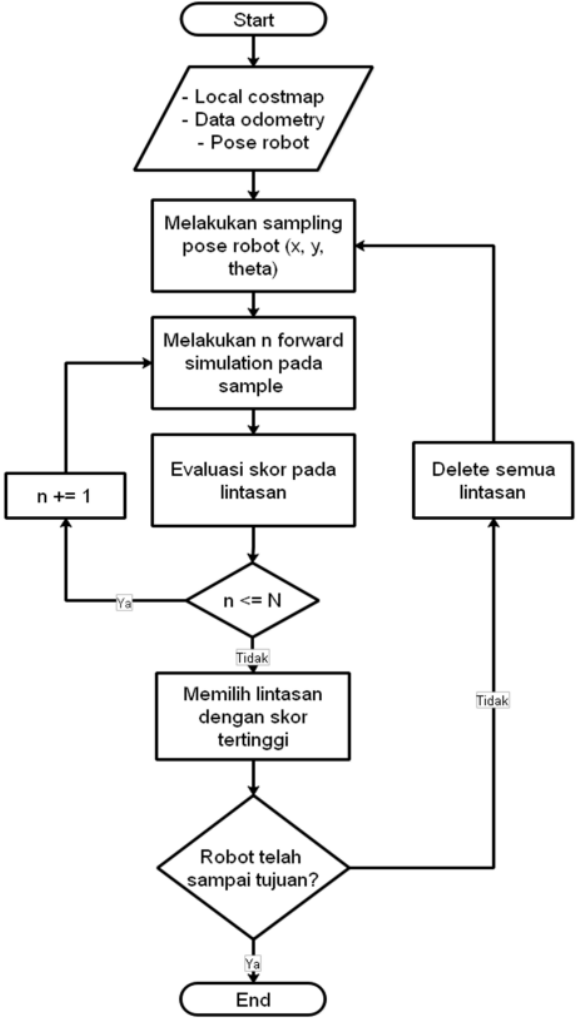

Gambar 5. Flowchart proses local 
Pengujian dilakukan dalam ruangan seperti pada gambar 6. Photo ruang pengujian. Dengan robot seperti pada gambar 7. Photo Mobile Robot.

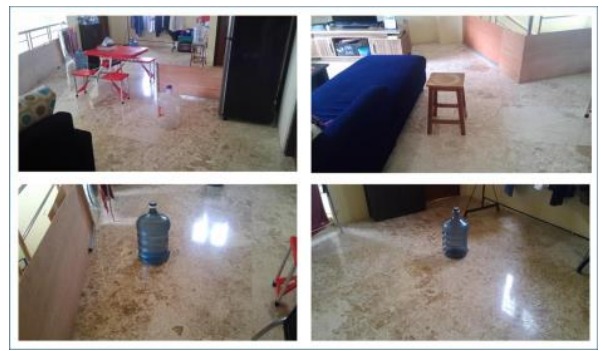

Gambar 6. Photo ruang pengujian

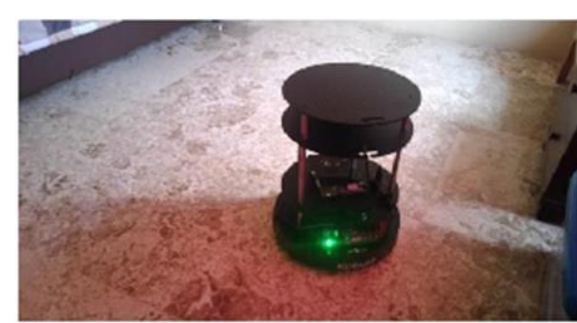

Gambar 7. Photo Mobile Robot

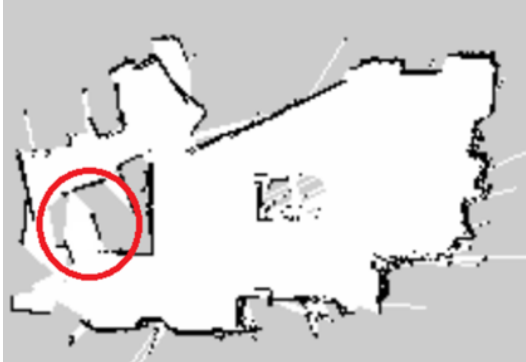

Gambar 9. Global mapping

Pengujian ditujukan untuk mengevaluasi kemampuan mobile robot dalam melaksanakan perintah "Sistem Navigasi Mobile Robot dalam ruangan berbasis Autonomous Navigation", pengujian dilakukan di dalam ruangan seperti pada gambar 6. Menggunakan Mobile robot seperti gambar 7. Sedangkan gambar 8. merupakan denah ruang pengujian yang menunjukkan lokasi pengujian yang harus dilalui oleh mobile robot.

Pada pengujian terhadap program SLAM dalam membentuk Global map (Gmapping) diperlihatkan pada gambar 9.

Pengujian dengan perintah untuk berkeliling dari titik A menuju B lanjut menuju C menuju ke D dan kembali ke A. Pengujian dilakukan sebanyak 5 kali dengan kecepatan mobile robot dibatasi dengan kecepatan maksimal $0.5 \mathrm{~m} / \mathrm{s}$, hasil pengukuran waktu tempuh serta kemampuan menghindari rintangan seperti pada tabel 1 .

Pengujian ketepatan mencapai posisi tujuan yang diperintahkan, diperoleh rata rata ketepatan untuk mencapai lokasi yang diperintahkan memiliki ketepatan yang baik yaitu dengan error rate sebesar $0,987 \%$

Tabel 1. Data hasil pengukuran wktu tempuh mobile robot

\begin{tabular}{|c|c|r|c|c|}
\hline \multirow{2}{*}{ No } & $\begin{array}{c}\text { Ke } \\
\text { Titik }\end{array}$ & $\begin{array}{c}\text { Waktu } \\
\text { Tempuh } \\
(\mathrm{s})\end{array}$ & Tabrakan & $\begin{array}{l}\text { Registrasi } \\
\text { rintangan }\end{array}$ \\
\hline \multirow{2}{*}{1.} & $\mathrm{~B}$ & 24.74 & Tidak & Ya \\
\cline { 2 - 5 } & $\mathrm{C}$ & 8.11 & Tidak & Ya \\
\cline { 2 - 5 } & $\mathrm{D}$ & 14.23 & Tidak & Ya \\
\hline
\end{tabular}




\begin{tabular}{|c|c|r|c|c|}
\hline & A & 11.45 & Tidak & Ya \\
\hline \multirow{4}{*}{2} & B & 24.46 & Tidak & Tidak \\
\cline { 2 - 5 } & C & 7.56 & Tidak & Tidak \\
\cline { 2 - 5 } & D & 14.84 & Tidak & Tidak \\
\hline & A & 11.12 & Tidak & Tidak \\
\hline \multirow{4}{*}{3} & B & 24.20 & Tidak & Tidak \\
\cline { 2 - 5 } & C & 7.63 & Tidak & Tidak \\
\hline & D & 13.78 & Tidak & Tidak \\
\hline & A & 10.84 & Tidak & Tidak \\
\hline \multirow{4}{*}{4} & B & 23.96 & Tidak & Tidak \\
\hline & C & 7.48 & Tidak & Tidak \\
\cline { 2 - 5 } & D & 10.65 & Tidak & Tidak \\
\hline & A & 24.14 & Tidak & Tidak \\
\hline \multirow{4}{*}{5} & B & 13.80 & Tidak & Tidak \\
\cline { 2 - 5 } & C & 7.54 & Tidak & Tidak \\
\cline { 2 - 5 } & D & 13.72 & Tidak & Tidak \\
\cline { 2 - 5 } & A & 10.60 & Tidak & Tidak \\
\hline
\end{tabular}

\section{KESIMPULAN}

Dari hasil penelitian yang merupakan Tugas Akhir dari Dwiky Erlangga ini, diperoleh kesimpulan sebagai berikut:

1. Mobile robot yang di-teleoperasikan oleh user melalui keyboard pada workstation dapat membangun map dari area yang tidak diketahui menggunakan algoritma SLAM gmapping memanfaatkan data depth dari sensor RGB-D camera yang dikonversi ke laser scan dengan akurasi tinggi meskipun mengalami odometry drift error yang mengakibatkan pose mobile robot mengalami jump.

2. Mobile robot dapat melakukan localization secara terus-menerus menggunakan algoritma AMCL, untuk kemudian melakukan global planning serta mampu untuk melakukan path replanning ketika global path awal tidak dapat mencapai titik tujuan.

3. Mobile robot dapat menghindari objek rintangan statis yang tidak terdapat pada peta dengan melakukan local planning oleh local planner forward simulation menggunakan algoritma Dynamic Window Approach ketika melakukan autonomous navigation.

4. Mobile robot dapat melakukan autonomous navigation secara konsisten ke 4 titik sebanyak lima putaran dengan total error rate sebesar $0.987 \%$.

\section{Saran}

Untuk pengembangan lebih lanjut pada penelitian selanjutnya dapat meningkatkan fleksibilitas navigasi mobile robot dengan mengembangkan kemampuan mapping dari mobile robot ketika melakukan navigasi terhadap objek-objek statis yang ada ketika peta dibuat sehingga mobile robot dapat mengenali perpindahan objek-objek statis tersebut dan memperbarui posisi objek-objek tersebut pada peta. 


\section{DAFTAR PUSTAKA}

a. R. Siegwart, "Introduction to Autonomous Mobile Robots", Cambridge, Massachusetts. Amerika Serikat : MIT Press, 2011, bab 1, hal.5

b. M. Boisy, et al., "Telepresence Robot for Home Care Assistance", AAAI Spring Symposium: Multidisciplinary Collaboration for Socially Assistive Robotics. Palo Alto, California. 2007. Hal: $50-55$

c. T.Pire et al., "Stereo Parallel Tracking and Mapping for robot localization", IEEE/RSJ International Conference on Intelligent Robots and Systems (IROS), 2015. Hal. 7478

d. R. Zapata et al., "Self-adaptive Monte Carlo Localization for Mobile Robots Using Range Finders", Robotica, 2012, hal. 229-244.

e. Q. Morgan et al., "ROS: an open-source Robot Operating System", dipresentasikan pada ICRA workshop on open source software, 2009, hal. 5 - 10.

f. F. Enrique et al, "Learning ROS for Robotics Programming", Edisi kedua, Birmingham, Inggris: Packt Publishing, 2015, bab 1-2, hal. 23-77.

g. S. Thrun et al., "Probabilistic Robotics", Cambridge, Massachusetts. Amerika Serikat: MIT Press, 2005, bab 1, bagian 1-2, hal. 3-8.

h. G. Grisetti et al., "Improved Techniques for Grid Mapping With Rao-Blackwellized Particle Filters", IEEE Transactions on Robotics, 2007, hal. 34-46.

i. G. Grisetti et al., "Improving Grid-based SLAM with Rao-Blackwellized Particle Filters by Adaptive Proposals and Selective Resampling", dipresentasikan pada IEEE International Conference on Robotics and Automation, Barcelona, 2005, hal.24322437.

j. $\quad$ S. Thrun et al., "Probabilistic Robotics", Cambridge, Massachusetts. Amerika Serikat: MIT Press, 2005, bab 8, bagian 2, hal. 250-267.

k. D. Fox, “Adapting the Sample Size in Particle Filters Through KLD-Sampling”, Internation Journal of Robotics Research, 2003, hal. 1-27 